\section{UJMM

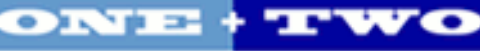

Volume 2 | 2010 Spring

\section{Undergraduate Journal of Mathematical}

Modeling: One + Two

2010

\title{
Optimization of a Chemical Reaction Train
}

\author{
Bahar Sansar \\ University of South Florida
}

\author{
Advisors: \\ Mile Krajcevski, Mathematics and Statistics \\ Scott Campbell, Chemical \& Biomedical Engineering \\ Problem Suggested By: Scott Campbell
}

Follow this and additional works at: https://digitalcommons.usf.edu/ujmm

Part of the Mathematics Commons

UJMM is an open access journal, free to authors and readers, and relies on your support:

Donate Now

\section{Recommended Citation}

Sansar, Bahar (2010) "Optimization of a Chemical Reaction Train," Undergraduate Journal of Mathematical Modeling: One + Two: Vol. 2: Iss. 2, Article 9.

DOI: http://dx.doi.org/10.5038/2326-3652.2.2.9

Available at: https://digitalcommons.usf.edu/ujmm/vol2/iss2/9 


\title{
Optimization of a Chemical Reaction Train
}

\begin{abstract}
This project consists of the optimization of a chemical reactor train. The reactor considered here is the continuous stirred tank reactor (CSTR), one of the reactor models used in engineering. Given the design equation for the CSTR and the cost function for a reactor, the following values are determined; the optimum number of reactors in the reaction train, the volume of each reactor and the total cost.
\end{abstract}

\section{Keywords}

Continuous Stirred Tank Reactor, Sequential Chain of Reactors, Optimization

\section{Creative Commons License}

(c) (i) $\Theta \Theta$

This work is licensed under a Creative Commons Attribution-Noncommercial-Share Alike 4.0 License. 


\section{TABLE OF CONTENTS}

Problem Statement

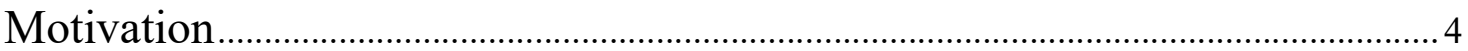

Mathematical Description and Solution Approach ………………………………....

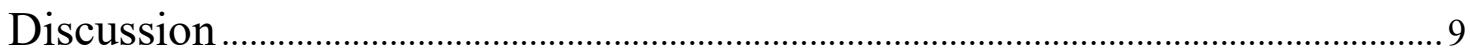

Conclusion and Recommendations..............................................................................

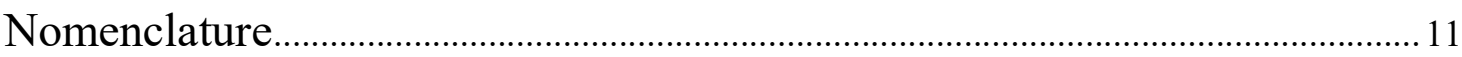

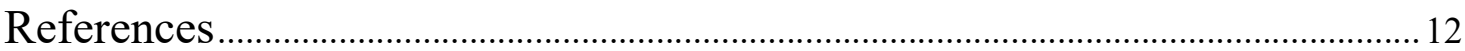

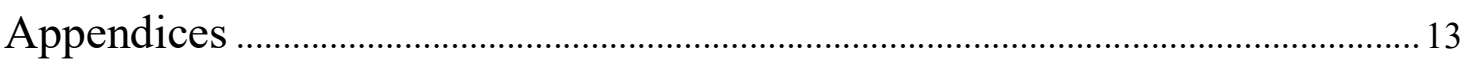




\section{PROBLEM STATEMENT}

One of the reactor models used in engineering is the CSTR (Continuous Stirred Tank Reactor). For a first order reaction $A \rightarrow B$, the design equation for the CSTR is:

$$
C_{A(\text { out })}=\frac{C_{A(\mathrm{in})}}{1+\frac{k V}{Q}}
$$

where $C_{A \text { (out) }}$ is the concentration of the reactant leaving the reactor and $C_{A \text { (in) }}$ is the concentration of reactant entering the reactor. These concentrations have units of moles $/ \mathrm{m}^{3}$. The quantity $Q$ is the volumetric flow rate of liquid (in $\mathrm{m}^{3} / \mathrm{hr}$ ) entering and leaving the reactor and $k$ is the first order rate constant in $h r^{-1}$. The volume of the reactor (in $m^{3}$ ) is represented by $V$. We are interested in a particular reaction involved in the manufacture of nylon. The first order rate constant is $0.9 / \mathrm{hr}$ and we wish to process $12 \mathrm{~m}^{3} / \mathrm{hr}$ of liquid. At the end of the process we want the concentration of $A$ to be $1 / 10,000$ of its starting value (i.e. $C_{A(\text { in })} / C_{A(\text { out })}=10,000$ ). The question is whether to do this with a single reactor or to chain reactors in series where the outlet from one reactor is the inlet to the next.

The cost function for a reactor is expressed by:

$$
\operatorname{Cost}(\$)=137,000 V^{0.4}
$$

where $V$ is the volume of the reactor. Assume that any reactors placed in a series would all have the same volume. Please determine the following:
a) The optimum number of reactors in the reaction train
b) The volume of each reactor
c) The total cost. 


\section{MOTIVATION}

This problem of optimizing a chemical reaction train is useful to science and engineering because "the most important unit operation in a chemical process is generally a chemical reactor." (ibiblio) Continuous stirred tank reactors (CSTRs) are used in many chemical experiments. In practice, "rapid reactions with reactive intermediates and products can be scaled up in the laboratory using continuously stirred tank reactors (CSTR)." (ACS Publications) According to Industrial Tomography Systems, "A CSTR consists of a stirred vessel that is heated in a controlled profile, stirred and after a fixed time cooled and discharged. They are widely used throughout the world wide process industries."

As an example, CSTRs can be used in the "generation of electricity and biogas from the waste water of slaughter house, animal and poultry, city sewage sludge, etc. where the content of organic waste is high." Further, "The fermentation of liquid and generation of biogas are made in an air-tight tank. A stirring device is installed in the digester so that the fermented material and microorganism are well mixed. The feeding of material is continuous or half-continuous under stable temperature. The newly fed material is stirred and mixed with the bacteria in the fermented liquid, resulting in the comparatively low density of the fermentation substrates." (Lipp Silo)

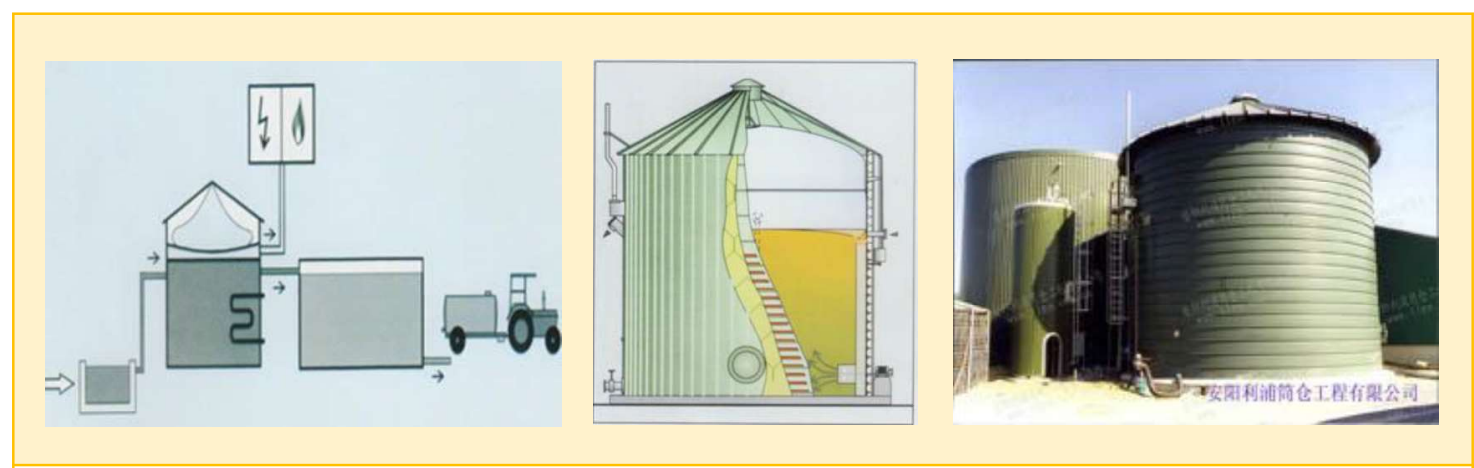

Figure 1: Two illustrations (left and center) and a photo (right) of a continuous stirred tank reactor. 
There are some advantages of CSTR such as "the low capital cost and the potential flexibility to make more than one product". (Industrial Tomography Systems) However, there are also some disadvantages like "the high energy usage/unit of product, variations in the degree of mixing and the fact that the reaction conditions vary throughout the batch tending to result in the creation of waste products." (Industrial Tomography Systems)

As mentioned above, a low capital cost can be an advantage; however it is important to know the number of reactors that should be used in series in order to optimize the cost of a specific CSTR. Millions of dollars can be saved by finding the optimum number or reactors. This is where calculus comes into play; it can be applied to deal with such problems. By taking the first and second derivative of the cost function relative to the number of reactors $n$, the optimum number of reactors can be found.

\section{MATHEMATICAL DESCRIPTION AND SOLUTION APPROACH}

The question for this problem is whether to do the project with a single reactor or to chain reactors in series where the outlet from one reactor is the inlet to the next one, assuming that any reactors placed in a series would all have the same volume. There are two possible options to resolve this problem: (1) a single reactor or (2) a chain of reactors in series. A comparison of the two options needed to find which is better suited for a particular enviroment.
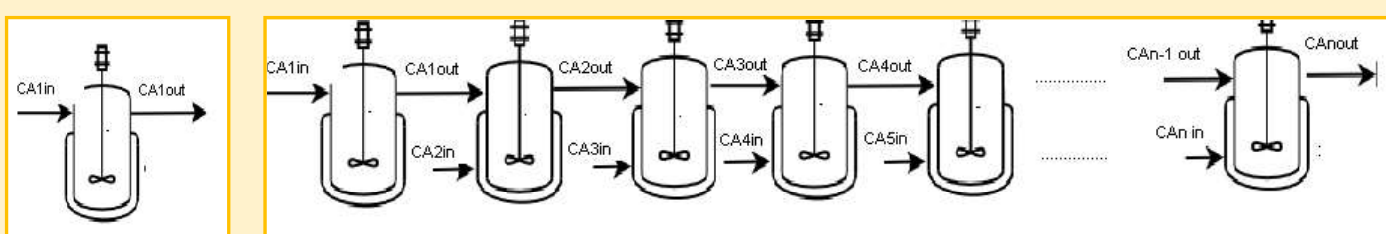

Figure 2: A single reactor (left) and a chain of reactors (right). 


\section{OPTION 1 - SINGLE REACTOR}

In this case there is only one reactor so it is simple to calculate the volume and costs associated with the reactor given the relationships defined in the problem statement. We have that

$$
C_{A(\text { out })}=\frac{C_{A(\text { in })}}{1+\frac{k V}{Q}}, \quad \frac{C_{A(\text { in })}}{C_{A(\text { out })}}=10,000 .
$$

Using $k=0.9 / h r$ and $Q=12 \mathrm{~m}^{3} / \mathrm{hr}$ together with the equations in (1) we can determine the volume of the reaction tank:

$$
10,000=\frac{C_{A(\text { in })}}{C_{A(\text { out })}}=1+\frac{k V}{Q}=1+\frac{3}{40} V
$$

and implies that $V=133,320 \mathrm{~m}^{3}$.

The relationship between the volume and the cost is given from the following equation:

$$
\text { Cost }=137,000 V^{0.4}=137,000(133,320)^{0.4} \approx \$ 15,370,170.64
$$

In summary, to achieve the desired concentrations with a single reactor the tank, it needs to be $133,320 \mathrm{~m}^{3}$ and will cost around $\$ 15.4$ million.

\section{OPTION 2 - CHAIN OF REACTORS IN SERIES}

For this option, the relationship between the concentration of the reactant leaving the final reactor $C_{A n \text { (out) }}$ and the concentration of the reactant entering the initial reactor $C_{A 1 \text { (in) }}$ is fixed, but the concentrations from the outlet of one reactor to the inlet of the next one is unknown.

In this setup, if there are $n$ reactors then

$$
C_{A 1(o u t)}=\frac{C_{A 1(i n)}}{1+\frac{k V}{Q}}, \quad C_{A 2(o u t)}=\frac{C_{A 2(i n)}}{1+\frac{k V}{Q}}, \quad C_{A 3(o u t)}=\frac{C_{A 3(i n)}}{1+\frac{k V}{Q}}, \ldots, \quad C_{A n(o u t)}=\frac{C_{A n(i n)}}{1+\frac{k V}{Q}}
$$


As seen in Figure 2, the concentration leaving reactor 1 is the same concentration entering reactor 2, the concentration leaving reactor 2 is the same concentration entering reactor 3 , and so forth. This means

$$
C_{A 1(\text { out })}=C_{A 2(\text { in })}, \quad C_{A 2(\text { out })}=C_{A 3(\text { in })}, \quad \ldots, \quad C_{A(n-1)(\text { out })}=C_{A n(\text { in })} .
$$

Combining the equations from (4) with (5), we get the general relationship

$$
C_{A i(o u t)}=\frac{C_{A i(i n)}}{1+\frac{k V}{Q}}=\left(1+\frac{k V}{Q}\right)^{-1} C_{A(i-1)(o u t)}
$$

for $2 \leq i \leq n$. Recursively applying (6), this can also be written as

$$
C_{A i(o u t)}=\left(1+\frac{k V}{Q}\right)^{1-i} C_{A 2(o u t)}=\left(1+\frac{k V}{Q}\right)^{-i} C_{A 1(i n)} .
$$

for $2 \leq i \leq n$. Thus, for $i=n$ we have

$$
C_{A n(o u t)}=\left(1+\frac{k V}{Q}\right)^{-n} C_{A 1(i n)}
$$

As in the single reactor option, we use the facts that $k=0.9 / \mathrm{hr}, Q=12 \mathrm{~m}^{3} / \mathrm{hr}$, and $C_{A 1(\text { in) }} / C_{A 1 \text { (in) }}=10,000$ to determine the volume of each reaction tank in the series:

$$
10,000=\frac{C_{A 1(\text { in })}}{C_{A n(\text { out })}}=\left(1+\frac{k V}{Q}\right)^{n}=\left(1+\frac{3}{40} V\right)^{n}
$$

Therefore the volume of each CSTR should be $V=\frac{40}{3}(\sqrt[n]{10,000}-1)$. Since the cost of each reactor is $137,000 V^{0.4}$ dollars, if $n$ reactors are used the cost is

$$
\text { Cost }=n\left(137,000 V^{0.4}\right)=(137,000 n)\left(\frac{40}{3}(\sqrt[n]{10,000}-1)\right)^{2 / 5} .
$$

We shall now minimize the cost function in (10) with respect to $n$ using derivatives. The first derivative is

$$
\begin{aligned}
\frac{d}{d n}[\text { Cost }] & =(137,000)\left(\frac{40}{3}\right)^{2 / 5} \frac{d}{d n}\left[n(\sqrt[n]{10,000}-1)^{2 / 5}\right] \\
& =(137,000)\left(\frac{40}{3}\right)^{2 / 5}\left((\sqrt[n]{10,000}-1)^{2 / 5}+n\left(\frac{2}{5}\right)(\sqrt[n]{10,000}-1)^{-3 / 5}\left(-\frac{\sqrt[n]{10,000} \log 10000}{n^{2}}\right)\right)
\end{aligned}
$$

Equation (12) represents the first derivative of the cost function for $n$ reactors in a series. 
It is hard to solve this equality (setting it equal to 0 ) analytically. Therefore, numerical methods are needed to find the optimal points.

The equations for the volume, cost, and the first derivative with their respective $n$ values were plugged into excel and the data was recorded in Appendix A. We can see that the cost is at its minimal values when $n$ is between 3 and 5 . There is a decrease in the cost value as $n$ goes from 3 to 4 and then the cost increases again as $n$ increases. Using the values of the first derivative obtained through trial and error, the optimal value of $n$ was found to be $n=4.1272$. However, $n$ represents the number of reactors places in a series and therefore it needs to be a positive integer. Therefore the optimum number of reactors in the reaction train is $n=4$, which is supported by the values in Table 1 . Note that the first derivative is decreasing for large values of $n$, but the cost continues to rise. We conclude that $n=4$ is a minimum while $n$ approaches a maximum as $n \rightarrow \infty$.

Given that $n=4$, the volume of each CSTR is $120 \mathrm{~m}^{3}$ and the associated cost is around $\$ 3.72$ million.

\section{COMPARISON OF OPTION 1 AND OPTION 2}

Option 1 require a tank of size $133,320 \mathrm{~m}^{3}$ and will cost $\$ 15,370,170.64$ while option 2 will require 4 tanks of size $120 \mathrm{~m}^{3}$ and will cost $\$ 3,719,230.18$. Clearly, option 1 will cost more than four times as much as option 2 and will take up over 277 times the volume. 


\section{DISCUSSION}

After comparing the two options for reducing the concentration of a reactant, the results showed that using four reactors with equivalent volumes minimizes the production cost.

For the single reactor option, the volume was calculated to be $133,320 \mathrm{~m}^{3}$ and the total cost to be $\$ 15,370,170.64$. For the series of reactors, the optimal number of reactors was found to be four, each having a volume of $120 \mathrm{~m}^{3}$ for which the total cost was $\$ 3,719,230.177$. Using four reactors in a series permitted the savings of millions of dollars: a net benefit of $\$ 11,650,940.46$. The minimum cost was found and project objective was met.

The number of reactors which minimized the cost was expected. Having only one reactor is a disadvantage since the cost is related to its volume. Using only one reactor requires a larger volume and, by their association, a higher cost. On the other hand if too many reactors are used in series, the volume is diminished but the cost of each reactor is expensive when all summed together. Therefore a few reactors (between 2 and 6) were expected.

The low cost of a continuous stirred tank reactor can be an advantage for industries. However, this process is streamlined by minimizing the cost. In this project, calculus techniques such as the first derivative test were used to find the optimal number of reactors in series allowing industries to save millions of dollars.

\section{CONCLUSION AND RECOMMENDATIONS}

This project concerned the optimization of a chemical reactor train. The design equation for the CSTR and the cost function for a reactor were given. After exploring two different possibilities and comparing them, the number of reactors that minimized the cost was established. 
With one reactor, the volume and the cost were easily determined. When a series of reactors were considered, a general formula relating the final concentration of the reactant leaving the final reactor and the initial concentration of the reactant entering the first reactor was found. This formula established a pattern between each concentration leaving the previous reactor and entering the pursuant reactor.

Calculus was used to determine the optimum number of reactors in the reaction train. Taking the first derivative of the cost function relative to the number of reactors and equating it to zero yielded the optimum number of reactors in the reaction train. Knowing the optimal number of reactors for this reaction train allowed us to find the volume of each reactor and the total cost.

This project shows that calculus can be applied to many different areas of chemistry. It permits one to determine the right number of reactors to use which minimized the cost of a chemical reactor which may potentially save millions of dollars.

Some recommendations for future researchers include starting the project by first visualizing the problem. Pictures of the reactors helped in having a better idea of the overall problem. Once the problem is understood, it can be interpreted in a mathematical way. It is also important to identify what is asked in the problem and to analyze the different methods available. In addition, writing down all the unknowns and the given relationships can make the problem simpler and expose patterns between the unknown values. 


\section{NOMENCLATURE}

\begin{tabular}{|c|c|c|}
\hline Symbol & Description & Unit \\
\hline$C_{A(i n)}$ & Concentration of the reactant entering the first reactor & moles $/ \mathrm{m}^{3}$ \\
\hline$C_{A 1(\mathrm{in})}$ & Concentration of the reactant entering reactor 1 & moles $/ \mathrm{m}^{3}$ \\
\hline$C_{A 2(\mathrm{in})}$ & Concentration of the reactant entering reactor 2 & moles $/ \mathrm{m}^{3}$ \\
\hline$C_{A 3(\text { in })}$ & Concentration of the reactant entering reactor 3 & moles $/ \mathrm{m}^{3}$ \\
\hline$C_{A n(i n)}$ & Concentration of the reactant entering reactor $n$ & moles $/ \mathrm{m}^{3}$ \\
\hline$C_{A(\text { out })}$ & Concentration of the reactant leaving the final reactor & moles $/ m^{3}$ \\
\hline$C_{A 1(\text { out })}$ & Concentration of the reactant leaving reactor 1 & moles $/ \mathrm{m}^{3}$ \\
\hline$C_{A 2(\text { out })}$ & Concentration of the reactant leaving reactor 2 & moles $/ m^{3}$ \\
\hline$C_{A 3(\text { out })}$ & Concentration of the reactant leaving reactor 3 & moles $/ \mathrm{m}^{3}$ \\
\hline$C_{A(n-1)(o u t)}$ & Concentration of the reactant leaving reactor $n-1$ & moles $/ \mathrm{m}^{3}$ \\
\hline$k$ & First order rate constant & $h r^{-1}$ \\
\hline$Q$ & Volumetric flow rate of liquid & $m^{3} / h r$ \\
\hline$V$ & Volume of each reactor & $m^{3}$ \\
\hline
\end{tabular}




\section{REFERENCES}

\section{BoOKS:}

Larson, Hostetler, Edwards. Calculus: Early Transcendental Functions. Fourth Edition. Houghton Mifflin Company. Boston, MA (2007).

\section{WEBSITES:}

ACS Publications. "Organic Process Research \& Development":

http://pubs.acs.org/doi/abs/10.1021/op0100605

ibiblio - The Public's Library and Digital Archive. "Continuous Stirred Tank Reactor": http://www.ibiblio.org/links/devmodules/cstr/index.html

Industrial Tomography Systems. "Fine Chemicals":

http://www.itoms.com/fine chemicals

Lipp Silo. "Continuous Stirred Tank Reactor":

http://www.lipp.com.cn/English/productshow1.asp?id=7 


\section{APPENDIX A - TABLES}

\begin{tabular}{|rrrr|}
\hline $\begin{array}{r}\text { Number of } \\
\text { Reactors }(n)\end{array}$ & Volume $\left(\mathrm{m}^{3}\right)$ & \multicolumn{1}{c}{ Cost $(\$)$} & $\begin{array}{c}\text { First } \\
\text { Derivative }\end{array}$ \\
\hline 1 & $133,320.00$ & $15,370,170.64$ & $-41,261,294$ \\
\hline 2 & $1,320.00$ & $4,852,663.04$ & $-2,088,282$ \\
\hline 3 & 273.93 & $3,880,558.66$ & $-372,302$ \\
\hline 4 & 120.00 & $3,719,230.18$ & $-21,731$ \\
\hline 5 & 70.79 & $3,764,349.33$ & 93,657 \\
\hline 6 & 48.56 & $3,884,755.37$ & 140,734 \\
\hline 7 & 36.37 & $4,037,439.01$ & 161,924 \\
\hline 8 & 28.83 & $4,204,851.22$ & 171,613 \\
\hline 9 & 23.77 & $4,378,810.75$ & 175,644 \\
\hline 10 & 20.16 & $4,555,160.98$ & 176,698 \\
\hline 50 & 2.70 & $10,186,708.44$ & 114,504 \\
\hline 100 & 1.29 & $15,151,922.20$ & 88,078 \\
\hline 1000 & 0.12 & $59,320,792.97$ & 35,483 \\
\hline & & & \\
\hline
\end{tabular}

Table 1: Volume, Cost, and First Derivative for a given number of reactors in a series. 


\section{APPENDIX B - CHARTS}

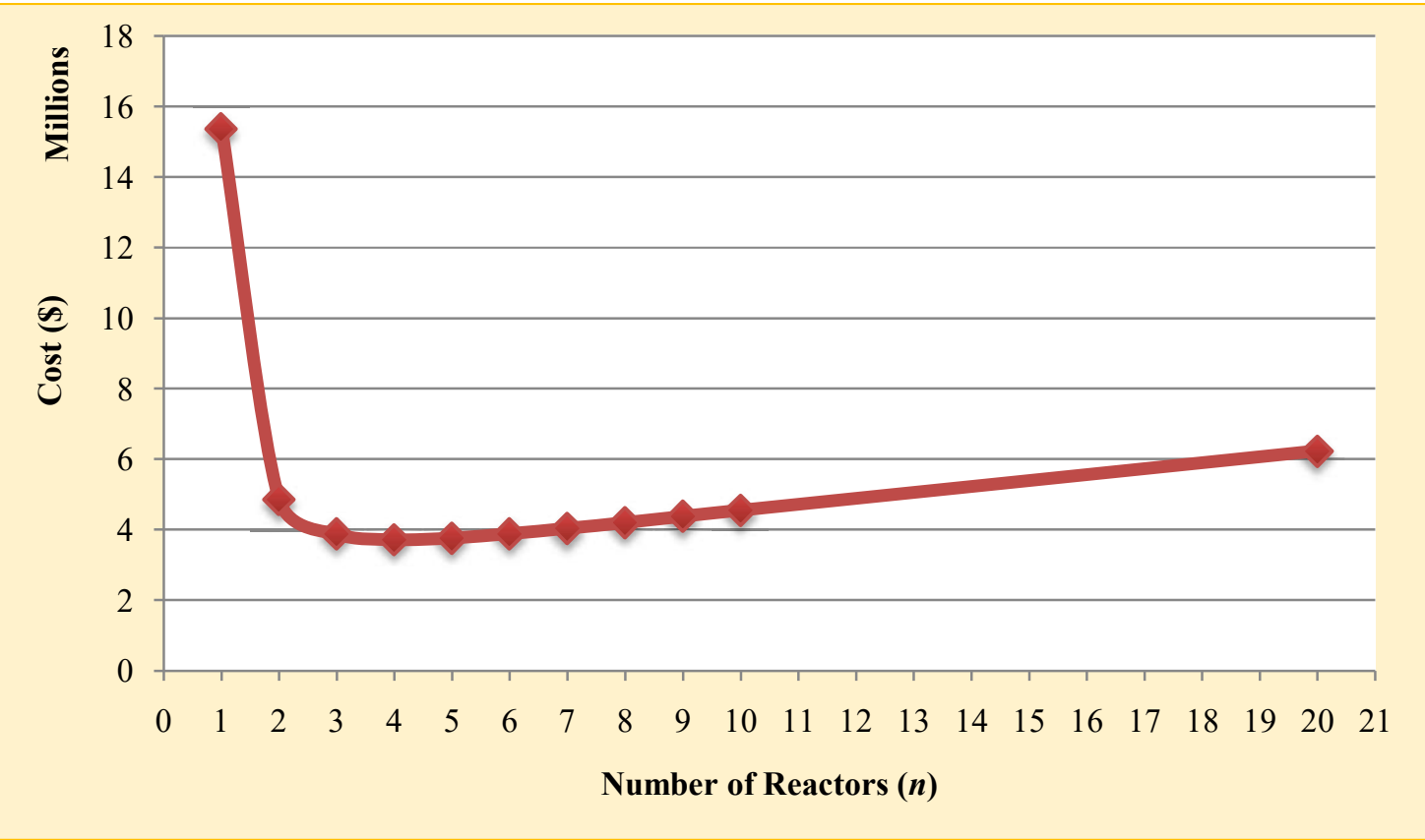

Table 1: Cost vs. Number of Reactors (in Series)

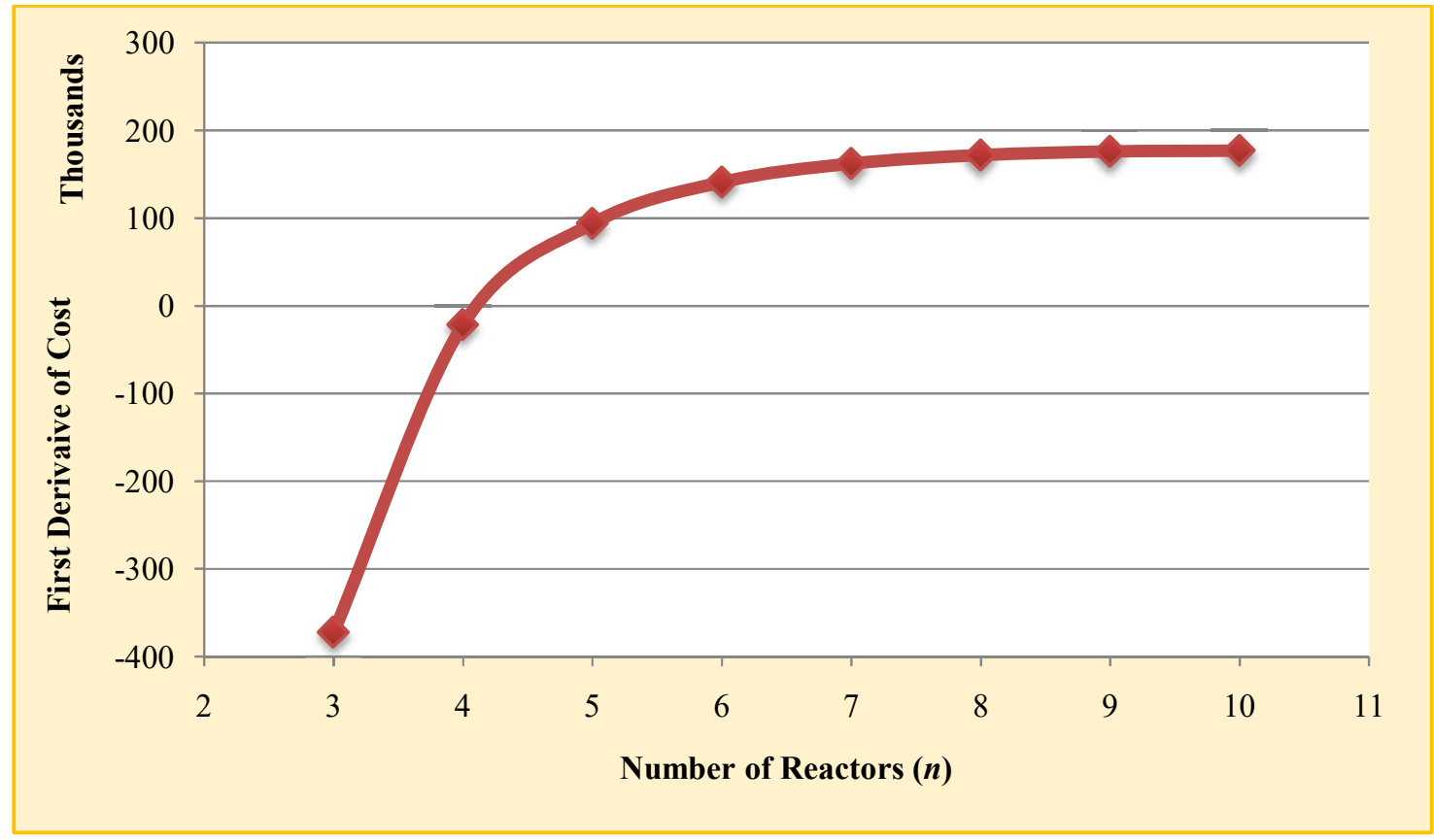

Table 2: First Derivative of Cost vs. Number of Reactors (in Series) 